\title{
Evaluation of serum hepcidin in assessment of iron status in renal transplant patients
}

\author{
Mohamed El-Khatib; May Fawzy; Sahier El-Khashab; Maher Fouad Ramzy; Dina Elgayar ${ }^{1}$ \\ and Manal Kamal ${ }^{1}$
}

Internal Medicine Department; Clinical and Chemical Pathology Department ${ }^{1}$, Faculty of Medicine, Cairo University, Cairo, Egypt.

\begin{abstract}
Background: Hepcidin is a 25 aminoacid peptide that is produced primarily by the liver in response to a variety of stimuli known to modulate tissue iron stores and its serum availability. It circulates in plasma, is filtered by the kidney, and accumulates in urine. The presence of hepcidin in the plasma negatively regulates the egress of iron from the cells and macrophages, involved in transport of iron into the extracellular spaces. Hepcidin binds to ferroportin 1 present on the cell surface leading to the internalization of ferroportin 1 and subsequent degradation. Hepcidin has also been shown to be an acute phase reactant increased by interleukin6 (IL-6) and markedly induced by infection and inflammation. Documentation of the role of hepcidin in the development of anemia in chronic kidney disease and whether it can be used as a marker of iron status in chronic kidney disease (CKD) has been sought in many studies.

The aim of this study was to detect the value of hepcidin as a marker of iron status in post renal transplant recipients as compared with chronic renal failure (CRF) patients on hemodialysis.

Results: In our study we found the level of serum prohepcidin in the renal transplant recipient group to be comparable to the control group. In the group with CKD the serum prohepcidin was significantly lower than controls as well as the transplant recipients (p-value: 0.00). There was no significant difference between the CKD group with higher hemoglobin and those with lower hemoglobin. From the correlation between the acute phase proteins and prohepcidin we found a positive correlation between serum ferritin, CRP and prohepcidin only in the group with CKD on hemodialysis.
\end{abstract}

Correspondence and offprint requests to: Dr. Mohamed El-Khatib, Internal Medicine Department, Faculty of Medicine, Cairo University, Cairo, Egypt.
Conclusion: We suggest that serum prohepcidin can be used as a routine measurement in transplant recipients as an indicator of the iron stores in the body. Further dedicated studies on large groups of patients need to be done to verify the usefulness of such a test.

\section{Introduction}

Body iron metabolism is based on a highly efficient system of iron conservation and recycling. Maintenance of body iron homeostasis requires mechanisms to control uptake and mobilization from stores to fulfill erythropoietic needs and to scavange used iron [1]. Recently major advances have been made in understanding the genetics of iron metabolism and this has led to identification of a number of new proteins involved in iron homeostasis. The discovery of hepcidin and subsequent research in the peptide has helped to provide a more functional view of iron metabolism and elucidate the mechanisms affecting iron status in patients with chronic inflammation and anemia [2].

Hepcidin is a 25 aminoacid peptide that is produced primarily by the liver in response to a variety of stimuli known to modulate tissue iron stores and its serum availability [3]. It circulates in plasma, filtered by the kidney, and accumulates in urine [4]. Hepcidin is synthesized as an 84 aminoacid prepropeptide which is subsequently processed into a 60-64 residue prohepcidin peptide and then finally into the mature biologically active 25 aminoacid hepcidin [5]. The presence of hepcidin in the plasma negatively regulates the egress of iron from the cells and macrophages, involved in transport of iron into the extracellular spaces [6]. Hepcidin binds to ferroportin 1 present on the cell surface leading to the ubiquitinization of ferroportin 1 and the lysosomal degradation of both proteins [7]. The loss of ferroportin decreases iron flow into plasma from 
absorptive enterocytes, from macrophages that recycle the iron of senescent erythrocytes and from hepatocytes that store iron there by lowering plasma iron concentration [8]. Deficient production of hepcidin causes systemic iron overload, whereas hepcidin excess, caused by many factors including inflammatory mediators as IL-6 leads to the development of hypoferrinemia and anemia of chronic disease [9]. Hepcidin has also been shown to be an acute phase reactant, increased by interleukin (IL)-6 and markedly induced by infection and inflammation [10].

Anemia of inflammation is characterized by a normocytic normochromic anemia associated with abnormal iron utilization, erythropoietin hyporesponsiveness, decreased red blood cell survival. The increased serum ferritin -indicative of increased macrophage iron stores, and decreased serum iron transferrin saturation-indicative of decreased macrophage iron recycling, suggests a condition of hepcidin excess [11].

It has been progressively evident that currently available iron indices do not reliably identify iron limited erythropoeisis [12]. This condition is often a sequela of chronic inflammation and since chronic kidney disease (CKD) is considered an inflammatory status [12], and since hepcidin is eliminated by the kidney [13], documentation of the role of hepcidin in the development of anemia in chronic kidney disease and whether it can be used as a marker of iron status in CKD has been sought in many studies.

Because hepcidin may convey important information about anemia and iron status, the aim of this study was to detect the value of hepcidin as a marker of iron status in post renal transplant recipients as compared with CRF patients on hemodialysis.

\section{Material and methods}

The patient population was selected from those who presented to the Hemodialysis Unit and the Renal Transplant Clinic, Cairo University, Faculty of Medicine Hospital, egypt.

The study was conducted on 15 renal transplant recipients who performed the operation two years previously, 35 chronic kidney disease patients (CKD) on chronic hemodialysis, and 10 healthy individuals who acted as controls.

The ethical committee of Cairo University approved the study and an oral consent was taken from all patients.

They were divided into three groups:

Group 1: Included 20 (CKD) patients on hemodialysis with a hemoglobin $>10 \mathrm{gm} / \mathrm{dl}$ their age was 50.+/- 9.1.

Group 2: Included 15 (CKD) patients on hemodialysis with a hemoglobin $<10 \mathrm{gm} / \mathrm{dl}$ their age was $44.4+/-16.8$.

Group 3: Included 15 renal transplant recipients whose hemoglobin was $>10 \mathrm{gm} / \mathrm{dl}$ their age was $27.2+/-14.6$. The patients underwent the transplant since 2 years and their creatinine ranged from 0.5-1.5.

Group 4: Included 10 normal healthy volunteers their age was $37.6+/-7.9$.
Exclusion criteria: Candidates that may affect iron status:

- Acute hemorrhage

- Pregnancy

- Liver cirrhosis

- Iron therapy

- Patients receiving blood transfusion

- Overt infections

All patients underwent a complete clinical evaluation followed determination of the hemoglobin level, the iron status and C.reactive protein.

\section{Evaluation of iron status:}

Serum iron and TIBC were measured on Hitachi 917 automated analyzer with kits purchased from Roche (Roche Diagnostics GmbH D-68298 Mannheim/ Germany).

Serum transferrin and CRP concentration were determined using nephelometry technique on BN Prospec by kit supplied by Siemens (Siemens HealthCare Diagnostics 1717 Deerfield Road Deerfield IL600150778)

TSAt was calculated using the following equation.

TSAt $(\%)=$ serum iron/transferrin $x 100$.

Serum ferritin was measured by chemiluminescent enzymatic immunometric assay on the Immulite Automated analyzer by kits supplied by DPC (Diagnostic products corporation 5700 West $96^{\text {th }}$ street Los Angeles, CA 90045-5597).

Serum pro-hepcidin was measured using hepcidin prohormone enzyme linked immunosorbant assay (ELIZA) purchased from DRG (DRG instruments, Marburg Germany) which was used as an indirect assessment of serum hepcidin.

\section{Statistical analysis:}

Data obtained from the study was coded and entered using the software SPSS (Statistical package for social science) version11.0 Quantitative parametric data was summarized using mean and standard deviation, while non parametric was summarized as median and percentiles. Comparison between groups was done using t-test and Mann Whitney were used to compare two groups, while ANOVA and Kruskal Wallis test were used to compare multiple groups. The correlation was done by Spearman's correlation coefficient.

$\mathrm{P}$-value is considered significant if $<0.05$.

\section{Results}

The mean serum level of Hepcidin was statistically significantly lower in the two CKD groups than those of the control group. It was statistically significantly higher in transplanted patients than that of the two CKD groups $(\mathrm{P}<0.01)$.

The mean serum level of CRP was statistically significantly higher in the CKD cases with $\mathrm{Hb}<10$ than 
those of the control group. It was statistically significantly lower in Transplanted patients than that the CKD cases with $\mathrm{Hb}<10$.

The mean serum level of $\mathrm{Hb}$ are statistically significantly lower in the the two CKD groups than those of control. It was statistically significantly higher in Transplanted patients than that of the CKD cases with $\mathrm{Hb}<10$.

The mean serum level of total iron saturation are statistically significantly higher in the CKD cases with $\mathrm{Hb}<10$ than those with $\mathrm{Hb}>10$ and control. It was statistically significantly lower in transplanted patients than that of the CKD cases with $\mathrm{Hb}<10$.
The mean serum level of TIBC was statistically significantly lower in the CKD cases with $\mathrm{Hb}<10$ than those with $\mathrm{Hb}>10$ and control. It was statistically significantly lower in transplanted patients than that of the control, table 1.

In the dialysis group, the CRP level showed statistically significant positive correlation with serum level of ferritin, and hepcidin levels $(\mathrm{r}=0.521,0.611$ and $\mathrm{P}<0.01$ respectively). Hepcidin level showed statistically significant positive correlation with serum level of ferritin ( $\mathrm{r}=0.517$ and $\mathrm{P}<0.01)$ (table 2$)$.

Table 1. The descriptive characteristics and biochemical data in the four groups.

\begin{tabular}{|c|c|c|c|c|c|}
\hline & Control, $n=10$ & $\begin{array}{l}H b>10 \text { (group } 1), \\
n=20\end{array}$ & $H b<10($ group 2$), n=15$ & Transplantation (group 3 ), $n=15$ & $P$ value \\
\hline Age & $34.4 \pm 6.8$ & $49.7 \pm 9.1^{*}$ & $44.4 \pm 16.7$ & $27.2 \pm 14.5^{\dagger \ddagger}$ & 0.000 \\
\hline Disease duration & $11.0 \pm 0.4$ & $13.8 \pm 4.5$ & $8.9 \pm 4.7$ & & 0.034 \\
\hline $\mathrm{Hb}, \mathrm{g} / \mathrm{dl}$ & $13.0 \pm 1.8$ & $11.9 \pm 1.4^{*}$ & $7.7 \pm 1.2^{* \dagger}$ & $12.4 \pm 1.7^{* \ddagger}$ & 0.000 \\
\hline Iron,ug/dl & $66.7 \pm 23.2$ & $68.2 \pm 29.1$ & $73.9 \pm 36.2$ & $79.4 \pm 36.7$ & 0.709 \\
\hline TIBC, ug/dl & $398 \pm 116.5$ & $232(194.2-357.7)^{*}$ & $163(149-219)^{* \dagger}$ & $309(276-440)^{\ddagger}$ & 0.000 \\
\hline Transferrin saturation, $\%$ & $17.8 \pm 6.5$ & $24.6 \pm 8.3$ & $40.7 \pm 21^{* \dagger}$ & $25.9 \pm 15.5^{\ddagger}$ & 0.001 \\
\hline Ferritin, $\mathrm{ng} / \mathrm{ml}$ & $40.5(16-206.9)$ & $202(94.6-545.7)^{*}$ & $680(282-1085)^{* \dagger}$ & $440(82-870)^{*}$ & 0.013 \\
\hline Hepcidin, ng/ml & $401.3 \pm 115.6$ & $240.5 \pm 85.2^{*}$ & $300.9 \pm 93^{*}$ & $408.8 \pm 83.7^{\dagger \ddagger}$ & 0.000 \\
\hline $\mathrm{CRP}, \mathrm{mg} / \mathrm{L}$ & $2(1-12)$ & $5.5(3-12)$ & $12(5-24)^{*}$ & $4(1-12)^{\ddagger}$ & 0.037 \\
\hline
\end{tabular}

*versus control, $\dagger$ versus group $1, \$$ versus group 2

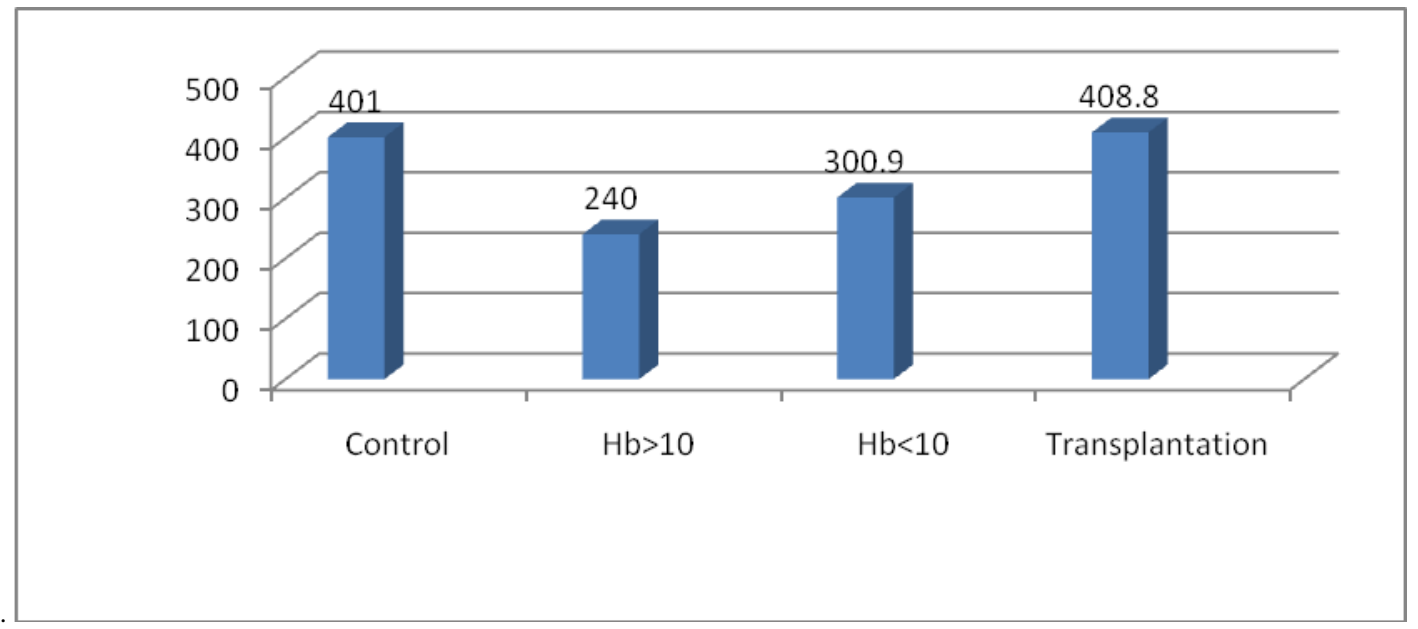

Fig. 1. Mean Hepcidin levels in different groups.

Table 2. Correlation study between iron, TIBC, CRP, hepcidin and ferritin in dialysis group.

\begin{tabular}{|c|c|c|c|c|c|c|}
\hline & & $C R P$ & Iron & $T I B C$ & Ferritin & Hepcidin \\
\hline \multirow[t]{2}{*}{ CRP } & $\mathrm{r}$ & - & 0.301 & -0.080 & 0.521 & 0.611 \\
\hline & $P$ & & 0.079 & 0.646 & 0.001 & 0.000 \\
\hline \multirow[t]{2}{*}{ Iron } & $\mathrm{r}$ & 0.301 & & 0.448 & -0.022 & 0.618 \\
\hline & $\mathrm{P}$ & 0.079 & - & 0.007 & 0.901 & 0.014 \\
\hline \multirow[t]{2}{*}{ TIBC } & $\mathrm{r}$ & -0.080 & 0.448 & & -0.337 & 0.246 \\
\hline & $\mathrm{P}$ & 0.646 & 0.007 & - & 0.048 & 0.376 \\
\hline \multirow{2}{*}{ Ferritin } & $\mathrm{r}$ & 0.521 & & -0.337 & - & 0.517 \\
\hline & $\mathrm{P}$ & 0.001 & $\begin{array}{l}-0.022 \\
0.901\end{array}$ & 0.048 & & 0.001 \\
\hline
\end{tabular}




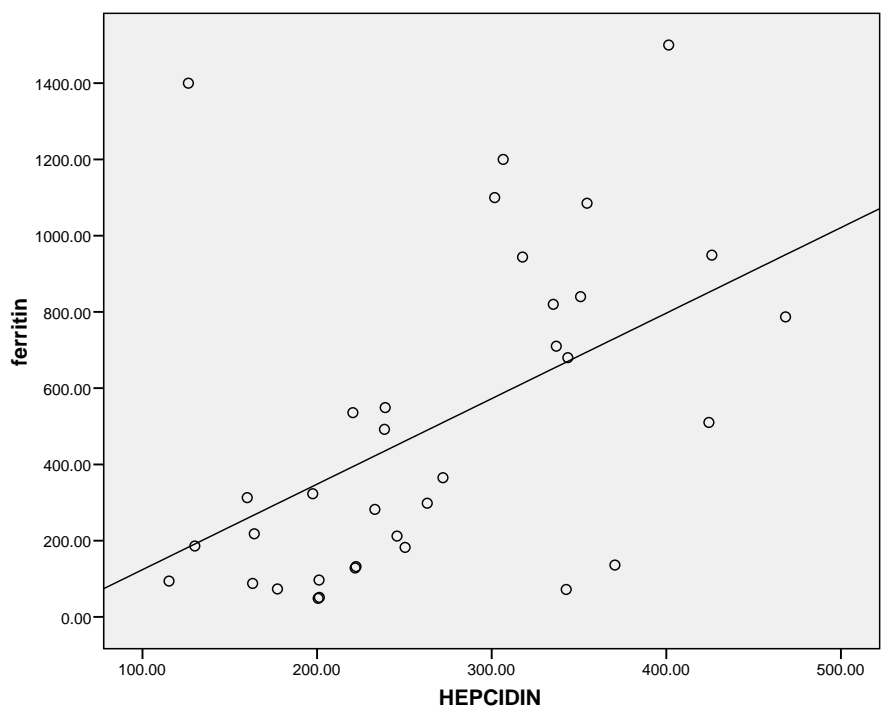

Fig. 2. Correlation between ferritin and hepcidin in chronic dialysis group.

Correlations in transplantation group ferritin with CRP showed significant positive correlation $(\mathrm{P}=0.038)$, table 3 .

Table 3. Correlation between the different parameters in transplantation group.

\begin{tabular}{|c|c|c|c|c|c|c|}
\hline & & $C R P$ & Iron & $T I B C$ & Ferritin & Hepcidin \\
\hline \multirow[t]{2}{*}{ CRP } & $\mathrm{r}$ & - & -0.395 & 0.611 & 0.539 & 0.084 \\
\hline & $\mathrm{P}$ & & 0.145 & 0.016 & 0.038 & 0.766 \\
\hline \multirow[t]{2}{*}{ Iron } & $\mathrm{r}$ & -0.395 & - & 0.448 & 0.325 & 0.192 \\
\hline & $\mathrm{P}$ & 0.145 & & 0.007 & 0.237 & 0.269 \\
\hline \multirow[t]{2}{*}{ TIBC } & $\mathrm{r}$ & 0.611 & 0.448 & - & 0.057 & -0.077 \\
\hline & $\mathrm{P}$ & 0.016 & 0.007 & & 0.840 & 0.659 \\
\hline \multirow{2}{*}{ Ferritin } & $\mathrm{r}$ & 0.539 & 0.325 & 0.057 & - & 0.218 \\
\hline & $\mathrm{P}$ & 0.038 & 0.237 & 0.840 & & 0.435 \\
\hline
\end{tabular}

\section{Discussion}

The discovery in 2001, that the liver derived peptide hepcidin plays a central role in the regulation of body iron homeostasis was a major advance in that field [15]. Since then multiple studies have elucidated the various aspects of involvement of hepcidin in iron limited anemia and in iron overload states. The measurement of hepcidin and its relation to inflammation in particular has been of great clinical significance. The condition known as Anemia of chronic disease ACD has been recognized by clinicians for decades but its cause and how to avoid it has till recently baffled researchers. Patients with chronic kidney disease (CKD) suffer from anemia in the course of their illness whether they are on dialysis or not. The cause of anemia in these patients is multifactorial and recently the role of hepcidin has been widely investigated .In our study we investigated the level of prohepcidin in patients with CKD on hemodialysis with different levels of hemoglobin as well as post renal transplant recipients with normal renal functions.

In our study we found the level of serum prohepcidin in the renal transplant recipient group to be comparable to the control group. In the group with CKD the serum prohepcidin was significantly lower than controls as well as the transplant recipients (p-value: 0.00). There was no significant difference between the CKD group with higher hemoglobin and those with lower hemoglobin. These findings were not consistent with other studies that found elevated levels of serum hepcidin in kidney allograft recipients, and attributed their findings to impaired renal functions and a low grade inflammatory state as reflected by hepcidin correlation with CRP, IL -6 and ferritin [16]. These findings also do not agree with studies done on cases with CKD that found a high level of serum hepcidin in CKD patients, and attributed their findings to a state of chronic inflammation as well as decreased clearance of hepcidin by the kidney $[12,17]$. But, our findings agree with another study that found serum prohepcidin to be lower in anemia of chronic disease [18].

In our study we studied the parameters of iron indices in our three groups. We found no evidence of hypoferremia in any of our study groups and there were no significant differences between the groups and the controls or with each other. The level of the TIBC on the contrary 
showed wide variations between the groups. In the renal transplant recipients the TIBC showed no significant difference with the controls and the transferrin saturation was normal. This is at variance with the group with CKD on hemodialysis whether their hemoglobin was above or below $10 \mathrm{~g} / \mathrm{dl}$. They had significantly lower TIBC than controls, despite the fact that their serum iron was within normal and comparable to the controls. The group with low hemoglobin had an even lower TIBC than the ones with higher hemoglobin and that was statistically significant (p-value: 0.00). The transferrin saturation in the CKD group was also within the normal range but showed significantly higher values in the group with lower hemoglobin levels.

Iron status in patients with CKD exhibits wide variations. There are patients with absolute iron deficiency in which a low serum iron is accompanied by a low transferrin saturation and a low serum ferritin. This condition is usually due to chronic blood loss from the gastrointestinal tract or increased tendency to bleed due to platelet dysfunction [19]. It may also be due to loss of blood during hemodialysis or poor intake and/or absorption of iron [20]. Then there are patients with functional iron deficiency in which a low serum iron is accompanied by a low transferrin saturation and a high serum feritin. This is due to intense stimulation of RBC production by erythropoietin [19]. Lastly are the patients with a dramatic increase in serum ferritin along with a drop in transferrin saturation which is termed Reticuloendothelial blockade. This condition is common in patients on dialysis with low grade chronic inflammation .It is due to impaired release of iron from its storage sites [21].

In this study the serum ferritin in the transplant recipient group was significantly elevated when compared to controls ( $\mathrm{p}$ value 0.01 ) but no significant difference with the CKD group, whose ferritin was also significantly more than the controls. The group with lower hemoglobin had a significantly higher ferritin than those with higher hemoglobin.

Ferritin is the cellular storage protein for iron [22]. It is synthesized by the body as a protective mechanism to bind iron which is toxic to cells in various tissue compartments. It is also an acute phase reactant protein, the serum level of which will rise nonspecifically during infections and inflammation [23]. In the normal adult serum ferritin is usually about $12-30 \mathrm{ug} / \mathrm{dl}$ while in dialysis patients with normal iron stores it is usually below $100 \mathrm{ug} / \mathrm{dl}$ [24].

In our transplant recipients the iron indices indicate a state of normal iron metabolism within the body. The exception is the serum ferritin. Renal transplantation is accompanied by endothelial dysfunction. In these patients, we found the CRP to be of normal value and yet there was a positive correlation between the ferritin and CRP in these patients. We summarize from this that elevated serum ferritin in these patients is not only an indicator of increased iron stores but may also be an acute phase reactant to chronic inflammation.
In the group with CKD the iron parameters indicate a state of increased iron stores in the body. Patients with CKD have a chronic inflammatory state including an enhanced incidence of infections, elevated levels of proinflammatory cytokines and factors related to hemodialysis [25]. The level of the CRP in our patients with CKD and with lower hemoglobin was significantly elevated than controls or transplant recipients ( $p$-value: 0.03 ). There was a positive correlation between CRP and serum ferritin. An increasing attention has focused on inflammation as a cause of anemia in CKD [26]. From these findings we observe a condition of functional iron deficiency which was less pronounced in the patients with high hemoglobin than those with lower hemoglobin. The serum prohepcidin in the CKD group showed a significant correlation with ferritin and CRP. These findings are in concordance with other studies that found a strong correlation with ferritin, CRP or both [12,16,27]. The serum prohepcidin in the renal transplant recipients, in our study did not correlate with either ferritin or CRP. Residual renal function seems to play a pivotal role in hepcidin levels in dialyzed patients. In addition the presence of low grade inflammation is more pronounced in anuric patients [28]. This statement may explain the higher levels of prohepcidin, ferritin and CRP in CKD patients with more pronounced anemia.

Despite the fact that our finding do not correlate with other studies approaching the same topic, we perceived from the data of our study that the serum prohepcidin was comparable to controls and did not correlate with parameters of inflammation, unlike the patients with CKD. Thus serum prohepcidin appears from this study to be a better indicator of the iron state than serum ferritin. We would like to recommend the routine measurement of serum prohepcidin or even better the level of serum hepcidin 25 in patients following renal transplantation as a marker of iron state in these patients.

There are certain limitations to our study which are quite similar to other studies as the rather small number of patients in the study, the use of prohepcidin protein measurement instead of the hepcidin protein, and the fact that all patients were iron replete.

In conclusion, serum hepcidin appears to be a missing link in the etiology of anemia of chronic diseases. It appears to be a reliable reflection of the iron status of the body and should be routinely measured in cases of anemia of iron deficiency. Therapies targeting the hepcidin gene or receptor should be sought with speed and accuracy to help improve the quality of life of such patients.

\section{References}

1. Finch C.: Regulators of iron balance in humans. Blood 1994; 84: 1697-1702.

2. Robson KJ.: Hepcidin and its role in iron absorption . Gut 2004; 53: 617-619.

3. Pigeon C., Ilyin G., Courselaud B. et al.L: A new mouse liverspecific gene encoding a protein homologous to human antimicrobial peptide hepcidin, is overexpressed during iron overload.J Biol.Chem. 2001; 276: 7811-7819. 
4. Pork CH., Vabre EV., Waring AJ., Ganz T.: Hepcidin a urinary antimicrobial peptide synthesized in the liver.J Biol. Chem. 2001; 276: 7806-7810.

5. Kemna EH., Tjalsma H., Willems HL., Swinkels OW.: Hepcidin: from discovery to differential diagnosis. Hematologica 2008; 93: 90-97.

6. Nicolas G., Bennoun M., Portea A et al.: Severe iron deficiency anemia in transgenic mice expressing liver hepcidin. Proc Natl Acad Sci USA 2002; 99: 4596-4601.

7. De Domenico I., Ward DM., Langelie C. et al.: The molecular mechanism of hepcidin mediated ferroportin down regulation. Mol. Biol. Cell. 2007; 18:2567-2578.

8. Nemeth E.: Targeting the hepcidin -ferroportin axis in the diagnosis and treatment of anemias. Adv. Hematol. 2010; 750643 E pub 2009 Dec 24.

9. Goswam T., Andrews NC.: Hereditary hemochromatosis protein HFE interaction with transferrin receptor 2 suggests a molecular mechanism for mammalian iron sensing .J boil. Chem. 2006; 281(39): 28494-28498.

10. Nemeth E., Tuttle MS., Powelson J. et al.: Hepcidin regulates iron efflux by binding to ferroportin and inducing its internalization. Science 2004; 306: 2090-2093.

11. Roy CN., Mak HH., Akpan I. et al.: Hepcidin antimicrobial peptide transgenic mice exhibit features of anemia of inflammation. Blood 2007; 109:4038-4044.

12. Zaritsky J., Young B. Wang. H. et al.: Hepcidin -A potential novel biomarker for iron status in chronic kidney disease $\mathrm{J}$ Am. Soc. Nephr. 2009; 4:1051-1056.

13. Nemeth E., Rivera S., Gabayan V. et al.: IL-6 mediates hypoferremia in inflammation by inducing the synthesis of the iron regulatory hormone hepcidin J Clin. Invest. 2004; 113:12711276.

14. Frazer DM. and Anderson G.: Hepcidin compared with prohepcidin: An absorbing story. AM. J Clin. Nutr. 2009; 89:475476.

15. Nicolas G., Bennoun M., Deavaux et al.: Lack of hepcidin gene expression and severe tissue iron overload in upstream stimulatory factor 2 (USF2) knock out mice. Proc. Natl. Acad.Sci. USA 2001 ; 98:8780-8785.
16. Malayszko J, Malyszko JS., Pawlak K., Mystiwiec M.: Hepcidin, an acute phase protein and a marker of inflammation in kidney transplant recipients with and without coronary artery disease. Transplant Proc. 2006; 38: 2895-2898.

17. Tomosugi N., Kawabata H., Wakatabe R., et al.: Detection of serum hepcidin in renal failure and inflammation by using protein chip system Blood 2006; 168:1381-1387.

18. Dallalio G., Fleury T., Means RT.Jr: Serum hepcidin in clinical specimens Br. J Haematol 2003; 122: 996-1000.

19. Fishbane S., Shapiro W., Dutka P. et al.: A randomized trial of iron deficiency testing strategies in hemodialysis patients. Kid. Int. 2001; $60: 2406-2410$

20. Besarab A., Amin N., Ahsan M. et al.: Optimization of epoetin therapy with intravenous iron therapy in hemodialysis patients. J Am. Soc. Nephr 2000; 11:530.

21. Bailie GR., Clark JA., Lane PL.: Hypersensitivity reactions and deaths associated with intravenous iron preparations. Nephrol. Dial.Transplant 2005; 20:1443.

22. Harrison PM., Arosio P.: The ferritins: Molecular properties iron storage function and cellular regulation Biochim.Biophys. Acta. 1996; 1275: 161-165.

23. Torti FM., Torti SV.: Regulation of ferritin genes and protein. Blood 2002; 99: 3505-3516.

24. Van Wyck DB., Cavalla G.,Spinowitz BS. Et al. Safety and efficacy of iron sucrose in patients sensitive to iron dextran: North American Clinical Trial. Am. J Kidney Dis. 2000: 36: 88-92.

25. Cappelli G., Tetta C., Canaud B.: Is boifilm a cause of silent inflammation in hemodialysis patients? A fascinating working hypothesis. Nephrol. Dial. Transplant, 2005; 20: 266-270.

26. Poole S., Bird TA., Selkirk S. et al.: Fate of injected interleukin 1 in rats sequestration and degradation in the kidney Cytokine, 1990; 2: 416-422.

27. Nemeth E., Valone EV., Territo M, et al.: Hepcidin, a putative mediator of anemia of inflammation is a type II acute phase protein Blood 2003;101:2461-2468.

28. Malyszko J., Malyszko JB., KOzminski P., Mysliwiec M.: Types of renal replacement therapy and residual renal function Ren. Fail. $2009 ; 31: 876-883$. 